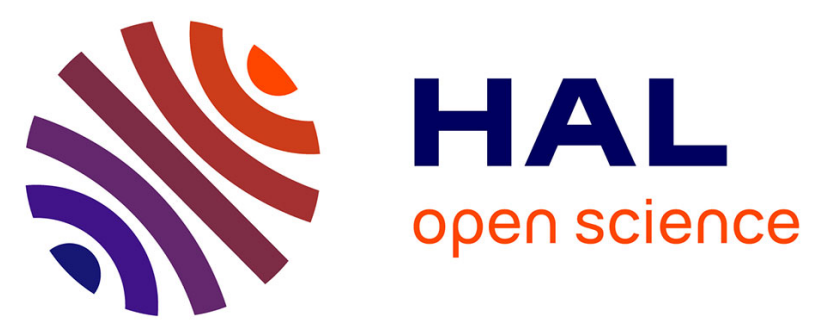

\title{
"Microscopic" and "Macroscopic" Level of the Errors for Detonation Characteristics Calculations: Pedigree of the Errors
}

\author{
T. Pivina, E. Arnautova, M. Molchanova, V. Shcherbukhin
}

\section{- To cite this version:}

T. Pivina, E. Arnautova, M. Molchanova, V. Shcherbukhin. "Microscopic" and "Macroscopic" Level of the Errors for Detonation Characteristics Calculations : Pedigree of the Errors. Journal de Physique IV Proceedings, 1995, 05 (C4), pp.C4-505-C4-517. 10.1051/jp4:1995441 • jpa-00253747

\section{HAL Id: jpa-00253747 https://hal.science/jpa-00253747}

Submitted on 1 Jan 1995

HAL is a multi-disciplinary open access archive for the deposit and dissemination of scientific research documents, whether they are published or not. The documents may come from teaching and research institutions in France or abroad, or from public or private research centers.
L'archive ouverte pluridisciplinaire HAL, est destinée au dépôt et à la diffusion de documents scientifiques de niveau recherche, publiés ou non, émanant des établissements d'enseignement et de recherche français ou étrangers, des laboratoires publics ou privés. 


\title{
"Microscopic" and "Macroscopic" Level of the Errors for Detonation Characteristics Calculations: Pedigree of the Errors
}

T.S. Pivina, E.A. Arnautova, M.S. Molchanova and V.V. Shcherbukhin

N.D. Zelinsky Institute of Organic Chemistry, Russian Academy of Sciences, Moscow 117913, Russia

\begin{abstract}
The detonation velocity is one of the principal characteristics of energetic materials. Therefore, computer search for structures of materials with high detonation velocity is a very urgent problem.

We formulated the following task: to elaborate a concept of computer design and subsequent screening of target structures with high detonation velocities.

The present state of this concept and the operation of the program package are illustrated by computer generation of novel energetic compounds, including caged skeletons. Using some optimum gross formulas, we use methods of mathematical chemistry for computer generation of isomeric structural formulas, which may correspond to potentially interesting substances with high detonation velocity. Then, using different methods (mostly original) for estimating the properties of these compounds, we calculate their physicochemical characteristics and recommend some of them for synthesis.

We also analyzed the possible sources of errors during calculation of some detonation characteristics and determined the possible error ranges for the calculated properties at the micro level (enthalpies of formation and molecular crystal densities). As a result, the total (macro level) errors in calculations of detonation parameters were determined.
\end{abstract}

\section{Introduction}

Methods of computer chemistry are presently widely used for predicting structures of substances with the given characteristics. This fact is easy to understand: computer has fantastic potentialities for enumerating structural isomers 
generated from the given molecular formula. For example, 217 isomers correspond to the composition $\mathrm{C}_{6} \mathrm{H}_{6}$. Thus, theoretical computer design and subsequent computer screening turn out to be more efficient (from the economic standpoint) than direct synthetic search.

In addition, the "computer brain" has no accepted stereotypes (which often determine the direction of search for specialists in synthetic chemistry), and we should expect that computer chemistry will provide us with nontrivial structures possessing extremum characteristics.

The objective of this study was computer search for structures of compounds with high detonation velocities.

However, solving the problem of computer screening for compounds with high detonation velocity, we encountered the problem of different errors in velocity calculations. These errors depend on the inaccuracy of estimating the physicochemical characteristics that are used for calculating the velocity: energy content and molecular crystal density of the structures in question. Therefore, we had to study how the errors emerging at the micro level of computer search for compounds with high detonation velocity (i.e., during calculations of formation enthalpies and molecular crystal densities) affect to accuracy of calculations with respect to macro level characteristics (the macro level is the level of computer screening by detonation velocities and subsequent selection of the target structures).

This study does not touch upon the mechanism of such a complex phenomenon as detonation. It only considers, so to say, the purely "pragmatic" aspects of the relationships between the molecular and macroscopic levels of this phenomenon: the relationship between the calculated characteristics of the micro level (enthalpy of formation and molecular crystal density) with the calculated characteristics of the macroscopic level.

So, we analyzed the possible sources of errors in such calculations by several particular examples, trying to trace the "pedigree" of the errors from the micro level to some detonation characteristics of the macro level.

\section{Methodology}

The present state of our concept and the program package for computer search of promising structure [1] are illustrated by Fig. 1. Using some optimum gross 


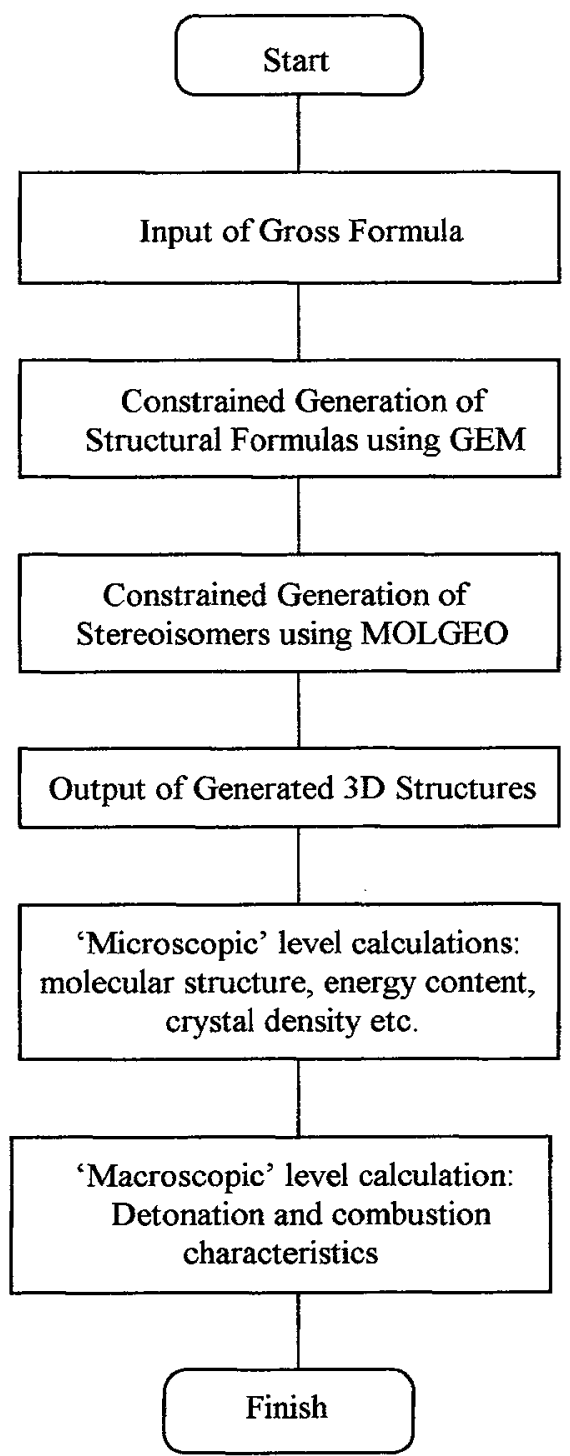

Fif. 1. The flow-chart of computer search for structures of target compounds. 
formula, we use mathematical chemistry to perform computer generation of isomeric structural formulas corresponding to potentially interesting substances with possibly high detonation velocity. Then, using different methods for estimating the properties of these compounds, we calculate their physical and chemical characteristics.

This study illustrates the whole concept of search for structures of high-energy compounds with high detonation velocities by the example of caged-type compounds from the adamantane and wurtzitane series.

The problem was formulated as follows: starting from the gross formulas of adamantane $\mathrm{C}_{10} \mathrm{H}_{16}$ and wurtzitane $\mathrm{C}_{12} \mathrm{H}_{18}$, find their potentially interesting nitroamino derivatives [2]. The principal parameter characterizing the compounds was their detonation velocity, which is known to be directly related to energy content and crystal density.

From the structural viewpoint, the energy content is determined [3] by the optimum number of quaternary and/or tertiary carbon atoms, tertiary nitrogen atoms, condensed rings, and also by the presence of explosophoric groups. The crystal density depends on the molecule's own symmetry and is usually higher for symmetrical molecules [4]

The first step consisted in the generation of constitutional isomers, represented by molecular graphs. Among all the molecular graphs that could be found for the given gross formulae of the adamantane and wurtzitane series, we considered only those which obeyed the restrictions specified in [2].

Using the GEM program [2] and the conditions for selecting the appropriate structures, we finally sorted out 11 isomers for the adamantane series and 49 isomers for the wurtzitane series. Afterwards, we estimated the energy content of these molecules by computational methods of quantum chemistry and selected 3 isomers from the adamantane series and 5 isomers from the wurtzitane series as the most promising. Then, we considered their hexaazahexanitro derivatives: namely, only those which preserved maximum molecular symmetry after the insertion of six nitroamino groups into the skeleton (Table 1).

At the second step, the MOLGEO [2] program converted the isomers from twodimensional molecular graphs into possible 3-dimensional molecular models. MOLGEO rapidly generates acceptable 3-dimensional Cartesian coordinates of 


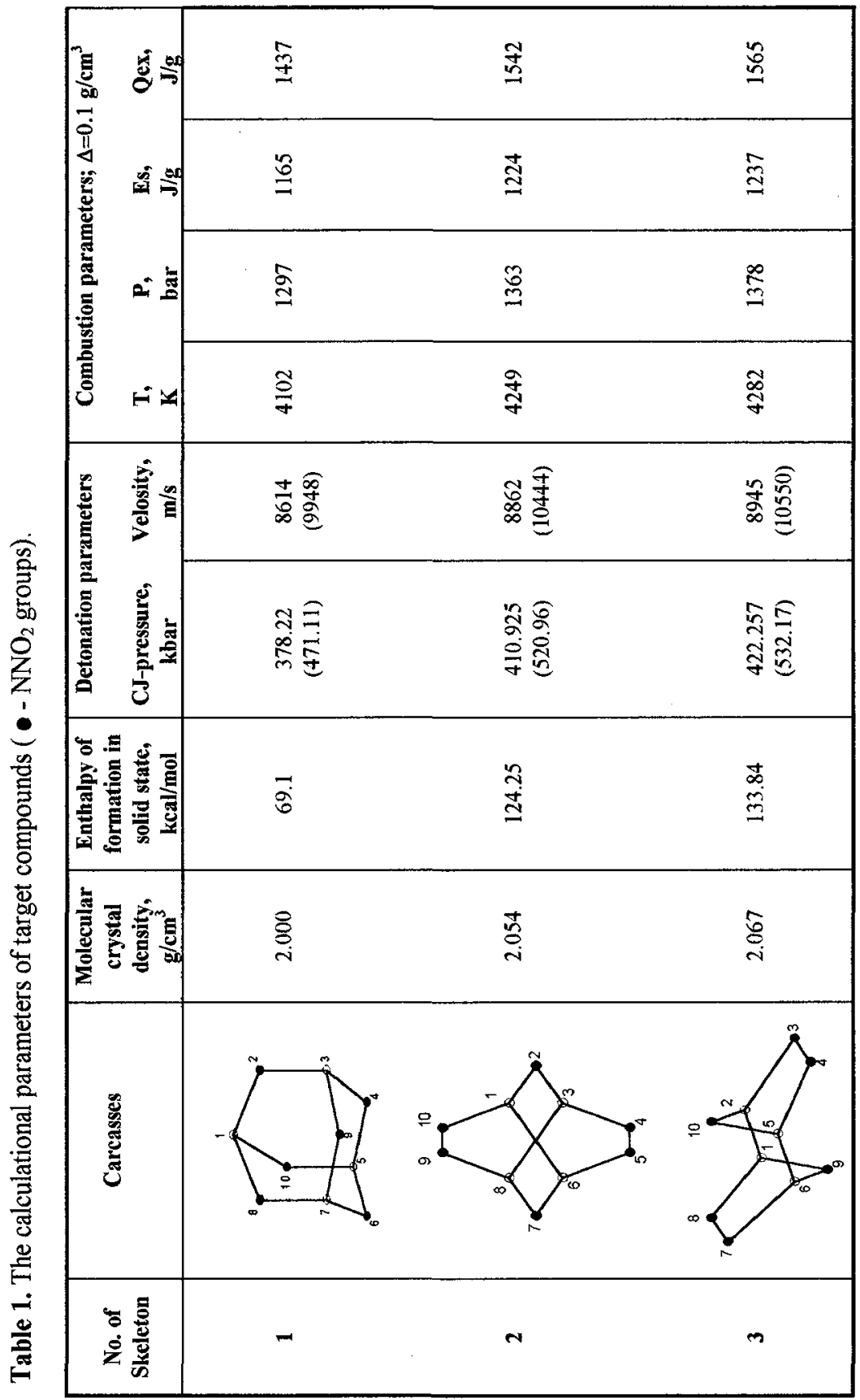




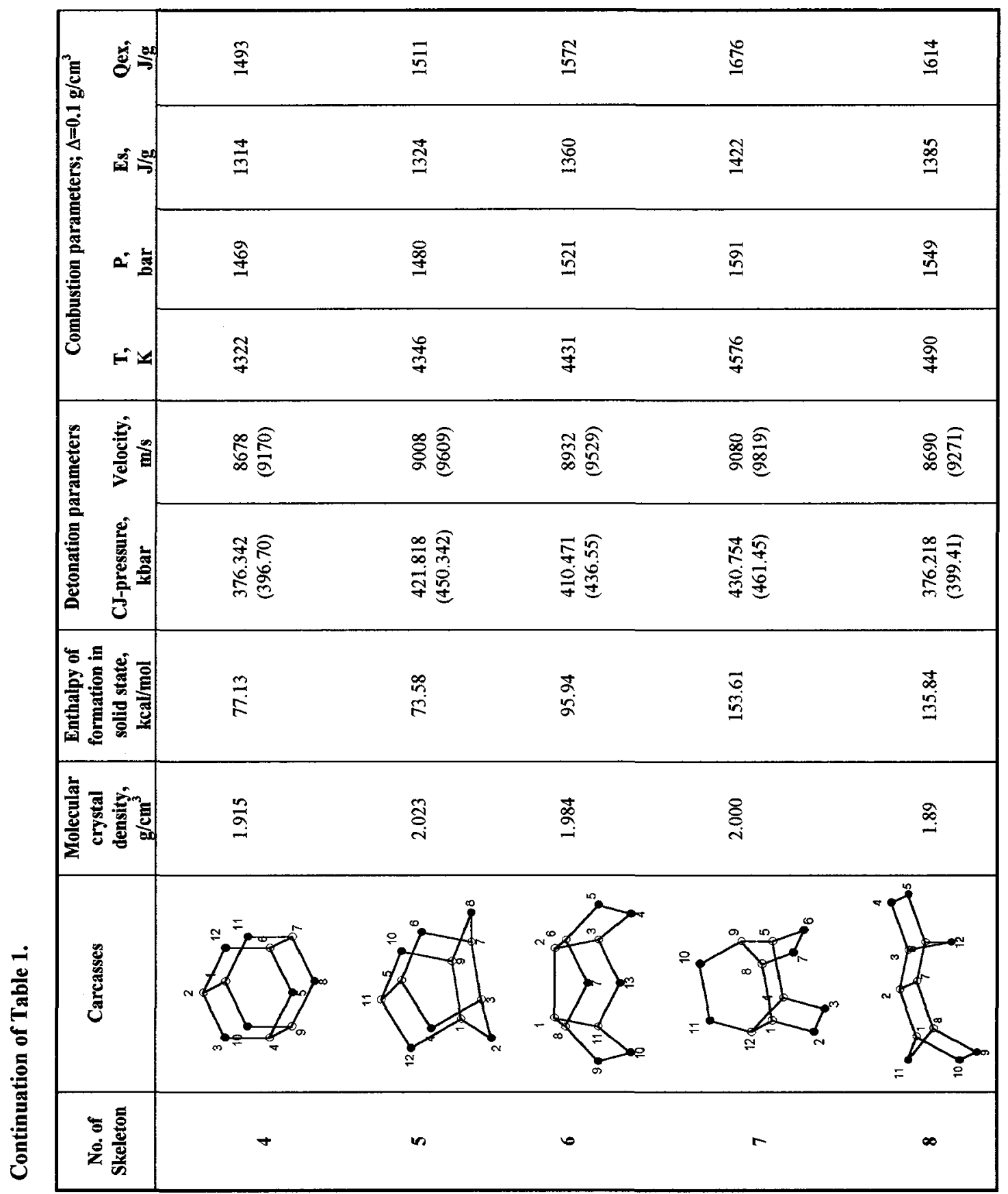


atoms according to the molecular connectivity table and the table of standard bond lengths and valence angles.

At the third step, the molecular geometry of the generated structures was refined, and the enthalpy of formation was estimated by subsequent application of the molecular mechanics method - the MM2 program [5] and the PM3 [6] quantum chemical method for the compounds in gas phase.

Then, we calculated molecular crystal densities of the resultant structures and their sublimation enthalpies, using the method of Atom-Atom Potential Functions (AAPF) [7,8]. Calculations of sublimation enthalpy for the crystals of the resultant compounds enabled us to estimate the energy content of these substances in the solid state and, afterwards, to calculate their detonation characteristics and combustion parameters.

However, the accuracy of estimating the detonation characteristics is very much dependent on the accuracy of calculating the energy content and molecular crystal density of the structures in question: Therefore, to reach our principal goal (the search for structures with high detonation velocities), we had to evaluate, so to say, the pedigree of the errors from the micro to the macro level. For this purpose, we first estimated this pedigree of errors by high-energy compounds, where a good experimental basis is available for such estimates and for "tracing" the resultant errors from the micro to the macro level. We selected hexogen (RDX) and octogen (HMX) as such "expert" compounds.

\section{Results and discussion}

Table 1 shows some characteristics of our compounds, as well as their principal calculated parameters of detonation and combustion.

On the whole, all the potential skeletons that obtained during directed computer generation have high detonation velocities. Among the compounds from the adamantane series, the hexaazahexanitro substituted frameworks N 3 (D $=8945$ $\mathrm{m} / \mathrm{s})$ and $\mathrm{N} 1(\mathrm{D}=8614 \mathrm{~m} / \mathrm{s})$ have the highest and lowest detonation velocities, respectively (Table 1). In the wurtzitane series, compounds $N 7(D=9080 \mathrm{~m} / \mathrm{s})$ and $N$ $4(D=8678 \mathrm{~m} / \mathrm{s})$ have the highest and lowest detonation velocities, respectively. 
Analyzing the results, we may note that hexanitrohexaazaisowurtzitane (CL20) has the high detonation velocity $(9.01 \mathrm{~km} / \mathrm{s})$ as calculated by the TIGER program package [9], or $9.61 \mathrm{~km} / \mathrm{s}$ as obtained by the scheme developed in $[10,11,12]$.

However, let us return to the combined effect of the errors in energy content and molecular crystal density calculations on the accuracy of detonation calculations. To consider this problem, let us analyze the calculated results for hexogen and octogen (Tables 2, 3). As follows from the results of our calculations, if the error in the enthalpy of hexogen formation is $1 \mathrm{kcal} / \mathrm{mol}$ (the experimental value - 17.0 $\mathrm{kcal} / \mathrm{mol}$ [13]), the error in the calculated detonation velocity is $4 \mathrm{~m} / \mathrm{s}$ (the experimental values are $8180 \mathrm{~m} / \mathrm{s}$ [14] and $8700 \mathrm{~m} / \mathrm{s}$ [15]). As the same time, if the error in molecular crystal density calculations is $0.02 \mathrm{~g} / \mathrm{cm}^{3}$, the corresponding error in $\mathrm{D}$ calculations is up to $68 \mathrm{~m} / \mathrm{s}$.

Similar results are also typical for the calculated detonation properties of octogen (the results are obtained for the $\alpha$-form of this compound): if the error in the calculated enthalpy of formation is $2 \mathrm{kcal} / \mathrm{mol}$ (the experimental value is $21.0 \mathrm{kcal} / \mathrm{mol}$ [13]) the inaccuracy of $\mathrm{D}$ calculations is $6 \mathrm{~m} / \mathrm{s}$; if the error in molecular crystal density calculations is $0.04 \mathrm{~g} / \mathrm{cm}^{3}$ (the experimental value is $1.84 \mathrm{~g} / \mathrm{cm}^{3}$ [14]), the inaccuracy of detonation velocity calculations is from 134 to $140 \mathrm{~m} / \mathrm{s}$.

Unfortunately, the data on physicochemical properties, combustion and detonation parameters of hexaazahexanitroisowurtzitane $(\mathrm{CL}-20)$ are not available from literature; therefore, we cannot estimate the pedigree of errors (at the macro and micro level) for CL-20. The calculated results for this compound are given in Table 4. If we take the calculated density $\left(2.1 \mathrm{~g} / \mathrm{cm}^{3}\right.$ [3] $)$ and the enthalpy of formation $(99.3$ $\mathrm{kcal} / \mathrm{mol}$ [16]), then the average inaccurasy of detonation velocity is $4 \mathrm{~m} / \mathrm{s}$ for the error in formation enthalpy of $2 \mathrm{kcal} / \mathrm{mol}$ and $127 \mathrm{~m} / \mathrm{s}$ for the density error of $0.04 \mathrm{~g} / \mathrm{cm}^{3}$.

Thus, results of our calculations and their analysis let us conclude that errors in the calculated detonation velocity mostly depend on errors in molecular crystal density calculations rather than on errors in energy content calculations.

\section{Conclusion}

It may be noted that errors in energy content calculations only moderately affect the resultant errors in calculations of detonation characteristics, whereas the effect of errors in molecular crystal density calculations is very notable. A logical conclusion 
Table 2

The results of the TIGER-calculations compared to results of calculations accoding to scheme $[10,11,12]$ (in brackets) for the hexagen (RDX)

\begin{tabular}{ccccc}
\hline & \multicolumn{5}{c}{$\mathbf{d = 1 . 7 5} \mathbf{g} / \mathbf{c m}^{\mathbf{3}}$} & & \\
\hline$\Delta \mathrm{H}_{\mathrm{f}}{ }^{\circ}, \mathrm{kcal} / \mathbf{m o l}$ & 15.0 & 16.0 & 17.0 & 18.0 \\
\hline $\mathrm{P}, \mathrm{kbar}$ & 334.3 & 334.7 & 335.2 & 335.6 \\
& $(332.2)$ & $(332.6)$ & $(333.1)$ & $(333.5)$ \\
\hline $\mathrm{D}, \mathrm{m} / \mathrm{s}$ & 8570 & 8574 & 8578 & 8582 \\
& $(8650)$ & $(8660)$ & $(8670)$ & $(8670)$ \\
\hline $\mathrm{T}, \mathrm{K}$ & 2568 & 2576 & 2585 & 2593 \\
\hline $\mathrm{I}$ & $(119.1)$ & $(119.2)$ & $(119.3)$ & $(119.4)$ \\
\hline
\end{tabular}

\section{$\Delta H_{\mathrm{f}}^{\circ}=15 \mathrm{kcal} / \mathrm{mol}$}

\begin{tabular}{cccccc}
\hline $\mathrm{d} . \mathrm{g} / \mathrm{cm}^{3}$ & 1.76 & 1.78 & 1.80 & 1.82 & 1.84 \\
\hline P. kbar & 338.5 & 347.0 & 355.7 & 364.6 & 373.4 \\
& $(336.6)$ & $(345.5)$ & $(354.5)$ & $(363.7)$ & $(373.0)$ \\
\hline $\mathrm{D}, \mathrm{m} / \mathrm{s}$ & 8604 & 8672 & 8740 & 8808 & 8876 \\
& $(8690)$ & $(8780)$ & $(8860)$ & $(8940)$ & $(9030)$ \\
\hline T, K & 2553 & 2521 & 2490 & 2457 & 2425 \\
\hline I & $(119.8)$ & $(121.3)$ & $(122.8)$ & $(124.3)$ & $(125.9)$ \\
\hline
\end{tabular}

$\Delta \mathbf{H}_{\mathrm{f}}^{0}=16 \mathrm{kcal} / \mathrm{mol}$

\begin{tabular}{cccccc}
\hline P. kbar & 339.0 & 347.5 & 356.1 & 364.9 & 373.9 \\
& $(337.0)$ & $(345.9)$ & $(355.0)$ & $(364.1)$ & $(373.5)$ \\
\hline D. m/s & 8608 & 8676 & 8743 & 8812 & 8880 \\
& $(8700)$ & $(8780)$ & $(8870)$ & $(8950)$ & $(9030)$ \\
\hline T, K & 2561 & 2530 & 2498 & 2466 & 2433 \\
\hline 1 & $(119.2)$ & $(121.4)$ & $(123.0)$ & $(124.5)$ & $(126.0)$ \\
\hline
\end{tabular}

$\Delta \mathbf{H}_{\mathrm{f}}^{\circ}=17 \mathrm{kcal} / \mathrm{mol}$

\begin{tabular}{|c|c|c|c|c|c|}
\hline P, kbar & $\begin{array}{r}339.4 \\
(337.5) \\
\end{array}$ & $\begin{array}{c}347.9 \\
(346.4) \\
\end{array}$ & $\begin{array}{r}356.6 \\
(355.4) \\
\end{array}$ & $\begin{array}{c}365.4 \\
(364.6) \\
\end{array}$ & $\begin{array}{c}374.3 \\
(374.0) \\
\end{array}$ \\
\hline $\mathrm{D}, \mathrm{m} / \mathrm{s}$ & $\begin{array}{c}8612 \\
(8710) \\
\end{array}$ & $\begin{array}{c}8679 \\
(8790) \\
\end{array}$ & $\begin{array}{c}8747 \\
(8870)\end{array}$ & $\begin{array}{c}8815 \\
(8960)\end{array}$ & $\begin{array}{c}8884 \\
(9040) \\
\end{array}$ \\
\hline $\mathrm{T}, \mathrm{K}$ & 2569 & 2538 & 2506 & 2474 & 2441 \\
\hline I & $(120.1)$ & $(121.6)$ & $(123.1)$ & $(124.6)$ & $(126.2)$ \\
\hline \multicolumn{6}{|c|}{$\Delta \mathrm{H}_{\mathrm{r}}^{0}=18 \mathrm{kcal} / \mathrm{mol}$} \\
\hline P, kbar & $\begin{array}{r}339.8 \\
(337.9) \\
\end{array}$ & $\begin{array}{c}348.3 \\
(346.8) \\
\end{array}$ & $\begin{array}{l}357.0 \\
355.9 \\
\end{array}$ & $\begin{array}{c}365.8 \\
(364.1) \\
\end{array}$ & $\begin{array}{r}374.8 \\
(374.5) \\
\end{array}$ \\
\hline $\mathrm{D}, \mathbf{m} / \mathbf{s}$ & $\begin{array}{c}8616 \\
(8710)\end{array}$ & $\begin{array}{c}8683 \\
(8800)\end{array}$ & $\begin{array}{c}8751 \\
(8800)\end{array}$ & $\begin{array}{c}8819 \\
(8960)\end{array}$ & $\begin{array}{c}8888 \\
(9050)\end{array}$ \\
\hline $\mathrm{T}, \mathrm{K}$ & 2578 & 2547 & 2515 & 2483 & 2450 \\
\hline I & $(120.2)$ & $(121.7)$ & $(123.2)$ & $(124.7)$ & $(126.3)$ \\
\hline
\end{tabular}




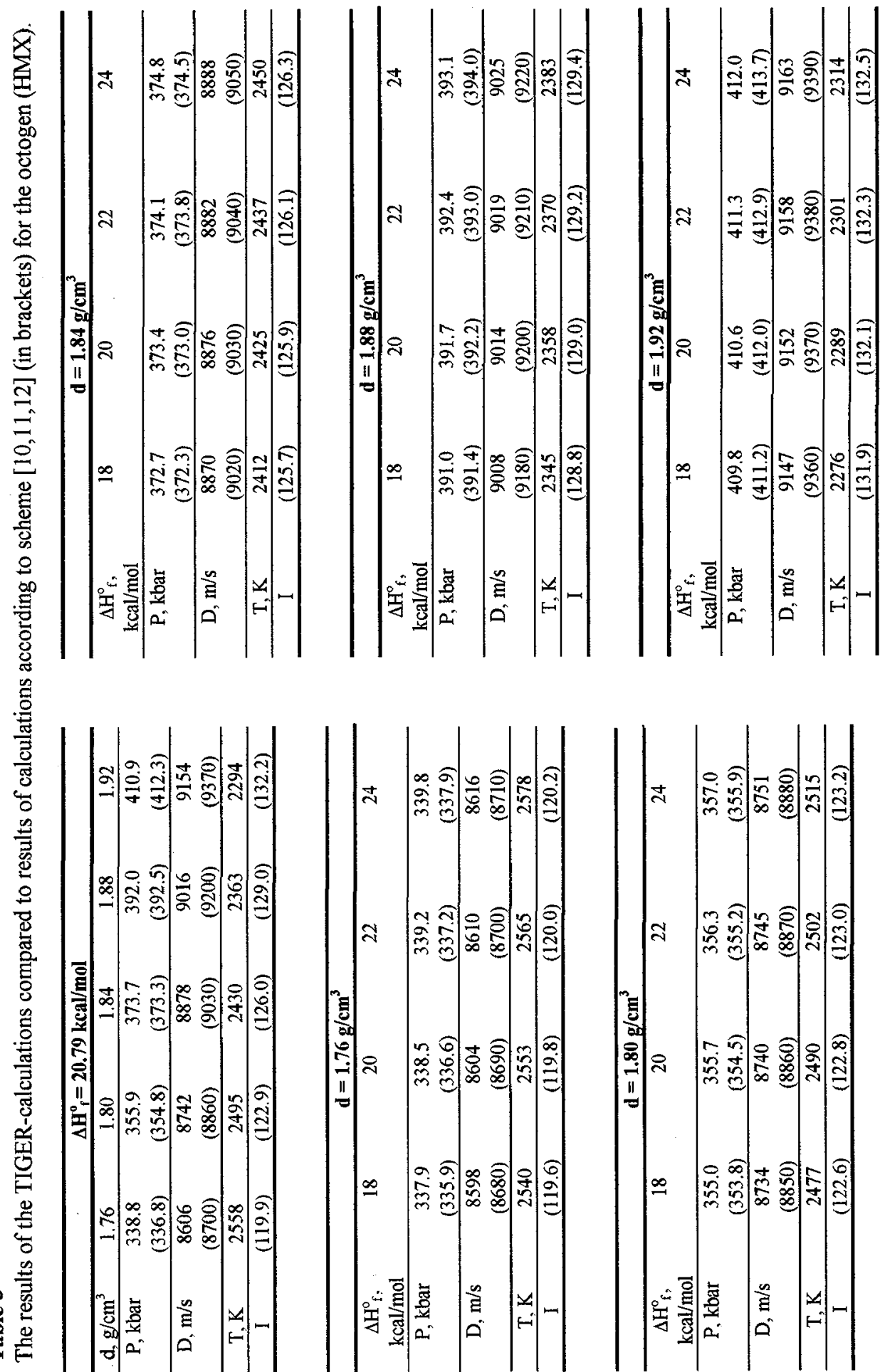


Table 4

The results of the TIGER-calculations compared to results of calculations accoding to scheme $[10,11,12]$ (in brackets) for the hexaazahexanitroizowurtzitane (CL-20).

\begin{tabular}{|c|c|c|c|c|c|}
\hline $\mathrm{d}, \mathrm{g} / \mathrm{cm}^{3}$ & 1.94 & 1.98 & 2.02 & 2.06 & 2.10 \\
\hline \multicolumn{6}{|c|}{$\Delta \mathrm{H}_{\mathrm{f}}^{\circ}=94 \mathrm{kcal} / \mathrm{mol}$} \\
\hline P, kbar & $\begin{array}{c}385.8 \\
(413.5)\end{array}$ & $\begin{array}{c}403.1 \\
(433.9)\end{array}$ & $\begin{array}{c}421.0 \\
(454.9)\end{array}$ & $\begin{array}{c}439.4 \\
(476.6)\end{array}$ & $\begin{array}{c}458.4 \\
(499.0)\end{array}$ \\
\hline $\mathrm{D}, \mathrm{m} / \mathrm{s}$ & $\begin{array}{r}8749 \\
(9330) \\
\end{array}$ & $\begin{array}{c}8874 \\
(9510) \\
\end{array}$ & $\begin{array}{c}9002 \\
(9680)\end{array}$ & $\begin{array}{r}9130 \\
(9850) \\
\end{array}$ & $\begin{array}{r}9261 \\
(10030) \\
\end{array}$ \\
\hline $\mathrm{T}, \mathrm{K}$ & 2830 & 2763 & 2694 & 2623 & 2550 \\
\hline I & (131.5) & $(134.6)$ & $(137.8)$ & $(140.9)$ & (144.2) \\
\hline \multicolumn{6}{|c|}{$\Delta \mathrm{H}_{\mathrm{f}}^{\circ}=100 \mathrm{kcal} / \mathrm{mol}$} \\
\hline P, kbar & $\begin{array}{r}387.2 \\
(414.2) \\
\end{array}$ & $\begin{array}{c}404.6 \\
(435.6) \\
\end{array}$ & $\begin{array}{r}422.5 \\
(456.7) \\
\end{array}$ & $\begin{array}{r}440.9 \\
(478.5) \\
\end{array}$ & $\begin{array}{c}460.0 \\
(500.9) \\
\end{array}$ \\
\hline $\mathrm{D}, \mathrm{m} / \mathrm{s}$ & $\begin{array}{c}8761 \\
(9360) \\
\end{array}$ & $\begin{array}{r}8886 \\
(9530) \\
\end{array}$ & $\begin{array}{c}9013 \\
(9700) \\
\end{array}$ & $\begin{array}{c}9141 \\
(9880) \\
\end{array}$ & $\begin{array}{c}9271 \\
(10050) \\
\end{array}$ \\
\hline $\mathrm{T}, \mathrm{K}$ & 2858 & 2791 & 2722 & 2651 & 2578 \\
\hline I & $(131.9)$ & $(135.0)$ & $(138.2)$ & $(141.4)$ & $(144.6)$ \\
\hline \multicolumn{6}{|c|}{$\Delta \mathrm{H}_{\mathrm{f}}^{\circ}=106 \mathrm{kcal} / \mathrm{mol}$} \\
\hline P, kbar & $\begin{array}{c}388.7 \\
(416.8) \\
\end{array}$ & $\begin{array}{c}406.1 \\
(437.3)\end{array}$ & $\begin{array}{c}424.0 \\
(458.5)\end{array}$ & $\begin{array}{c}442.5 \\
(480.4) \\
\end{array}$ & $\begin{array}{r}461.5 \\
(502.9) \\
\end{array}$ \\
\hline $\mathrm{D}, \mathrm{m} / \mathrm{s}$ & $\begin{array}{r}8772 \\
(9380) \\
\end{array}$ & $\begin{array}{r}8897 \\
(9550) \\
\end{array}$ & $\begin{array}{r}9024 \\
(9730) \\
\end{array}$ & $\begin{array}{r}9152 \\
(9990) \\
\end{array}$ & $\begin{array}{r}9282 \\
(10080) \\
\end{array}$ \\
\hline $\mathrm{T}, \mathrm{K}$ & 2886 & 2819 & 2750 & 2679 & 2606 \\
\hline I & $(132.3)$ & (135.4) & $(138.6)$ & (141.8) & (145.1) \\
\hline \multicolumn{6}{|c|}{$\Delta \mathrm{H}_{\mathrm{f}}^{\circ}=110 \mathrm{kcal} / \mathrm{mol}$} \\
\hline $\mathrm{P}, \mathrm{kbar}$ & $\begin{array}{r}390.0 \\
(417.8) \\
\end{array}$ & $\begin{array}{c}407.0 \\
(438.4) \\
\end{array}$ & $\begin{array}{c}416.0 \\
(459.7) \\
\end{array}$ & $\begin{array}{r}443.5 \\
(481.6) \\
\end{array}$ & $\begin{array}{c}462.6 \\
(504.2) \\
\end{array}$ \\
\hline $\mathrm{D}, \mathrm{m} / \mathrm{s}$ & $\begin{array}{c}8780 \\
(9390)\end{array}$ & $\begin{array}{c}8905 \\
(9570)\end{array}$ & $\begin{array}{c}8968 \\
(9740) \\
\end{array}$ & $\begin{array}{c}9159 \\
(9920)\end{array}$ & $\begin{array}{c}9289 \\
(10100)\end{array}$ \\
\hline $\mathrm{T}, \mathrm{K}$ & 2904 & 2838 & 2804 & 2698 & 2625 \\
\hline I & $(132.6)$ & $(135.7)$ & $(138.9)$ & $(142.1)$ & $(145.4)$ \\
\hline
\end{tabular}


follows: high-precision calculations of detonation characteristics at the macro level require accurate calculations of the molecular crystal density. To a smaller degree, the errors depend on the inaccuracies in determining the energy content of compounds.

On the whole, we should note that our concept of computer search for structures of compounds with high detonation velocities may be efficiently used both for computer generation (with subsequent screening) by other molecular formulas and for computer search aimed at structures with other desired properties (for example, high impulse of launching ability, definite heat stability, or given sensitivity parameters).

\section{References}

(1) T.S.Pivina, V.V.Shcherbukhin, M.S.Molchanova, E.A.Arnautova, A.V.Dzyabchenko, I.A.Suslov. "The Elaboration of an Ab Initio Method for Structural Generation of Synthones Aimed at Creating Energetic Materials", in Proc. of the 20th IPS, Colorado Springs, US, 797(1994).

(2) T.C.Pivina, M.S.Molchanova, V.V. Shcherbukhin, N.S.Zefirov. "Computer Generation of Caged Frameworks Which Can be Used as Synthons for Creating High-Energetic Materisals", Propellants, Explosives, Pyrotechnics 19, 1994.

(3) A.T.Nielsen. Polycyclic Amine Chemistry, in: G.A.Olah and D.R.Squire (Eds.) "Chemistry of Energetic Materials", Academic Press, Inc., 1991.

(4) T.S.Pivina, V.A.Shlyapochnikov. "A Heuristic Model for Computer Prediction of Molecular Crystals with High Density", Zh. Fiz. Khim., 66, 1, 84 (1992).

(5) T.Clark. "A Handbook of Computational Chemistry", John Willey \& Sons, Inc., 1985.

(6) AMPAC CODE (Version 1.00).

(7) A.I.Kitaigorodsky. Molecular Crystals and Molecules. Academic Press: New York, London, 1973.

(8) N.E.Kuzmina, N.A.Pirogova, T.S.Pivina, V.A.Shlyapochnikov. "Analysis of Potential Energy Surfaces for Crystals of Poly-Nitro Compounds", Zh. Fiz. Khim., $66,1,101$ (1992). 
(9) M. Cowperthwaite, W.H. Zwisler. "TIGER Computer Program Documentation", SRI Publication, No. Z106, 1973.

(10) V.I. Pepekin, M.N. Makhov, Yu.A. Lebedev. Dokl. Akademii Nauk, 232, 4, 852 (1977).

(11) V.I. Pepekin, N.M. Kuznetsov, Yu.A. Lebedev. Dokl. Akademii Nauk, 234, 1, 105 (1977).

(12) V.I.Pepekin, Yu.A. Lebedev. Dokl. Akademii Nauk, 234, 6, 1391 (1977).

(13) G.Krien, H.H.Licht, J.Zierath. Thermochemische Untersuchungen an Nitraminen, Thermochimica Acta, 6(1973), 465-472.

(14) Properties of Explosives of Military Interest, Army Material Command, AMC pamphlet, 706-177 (1971).

(15) D.R.Hardesty, D.E.Kennedy. Thermochemical Estimation of Explosive Energy Output, Combustion and Flam 28, $45-59$ (1977)

(16) S.Bourasseau. A systematic Procedure for Estimating the Standart Heats of Formation in the Condensed State of Non Aromatic Polynitro Compounds. Journal of Energetic Materials, vol.8, 416-441 (1990). 